\title{
Guidelines for Osteoprotection in Breast Cancer Patients on an Aromatase Inhibitor
}

\author{
Peyman Hadji \\ University Hospital for Obstetrics and Gynecology, Philipps-University of Marburg, Germany
}

\section{Key Words}

Breast cancer - Fracture - Aromatase inhibitors . Bone loss · Bone mineral density

\section{Summary}

Postmenopausal women are at an increased risk of osteopenia and osteoporosis due to the physiologic loss of the bone protective effects of estrogen. Additionally, disease-related risk factors also contribute to the increased fracture risk. To further complicate matters, one of the most common and severe safety issues associated with cancer therapies for breast cancer patients is bone loss and the associated increased risk of fractures. These facts underscore the need to carefully monitor bone mineral density in patients with endocrine-responsive breast cancer, and to consider adjuvant therapy that may help manage and/or prevent bone loss and fracture. Aromatase inhibitors (Als) are now in widespread clinical use for women with hormone receptor-positive breast cancer and have replaced tamoxifen as the gold standard of care. Als target the estrogen biosynthetic pathway and deprive tumor cells of the growth-promoting effects of estrogen. These treatments provide significant benefit to patients in terms of improved disease-free and overall survival. Adversely, there is a concern of an increased risk of bone loss with prolonged therapy consequently leading to an increased fracture risk. This manuscript will review the recent literature pertaining to $\mathrm{Al}$-associated bone loss and discuss suggested management and preventative approaches that may help patients remain on therapy to derive the most clinical benefits.

\author{
Schlüsselwörter \\ Brustkrebs · Fraktur - Aromatase Inhibitor . \\ Knochendichteverlust · Knochendichte
}

\section{Zusammenfassung}

Postmenopausale Frauen weisen ein erhöhtes Lebenszeitrisiko für eine Osteoporose auf, bedingt durch den physiologischen Verlust des knochenprotektiven Effekts der Östrogene nach der Menopause. Des Weiteren können Risikofaktoren sowie den Knochenstoffwechsel beeinflussende Erkrankungen und Medikamente das Frakturrisiko weiter erhöhen. Zusätzlich kommt es durch die Standardtherapien in der Behandlung von Frauen mit Brustkrebs zu einer weiteren Verschärfung des Problems mit einem weitergehenden Verlust an Knochendichte sowie einem Anstieg des Frakturrisikos. Hieraus ergibt sich die Notwendigkeit, das individuelle Frakturrisiko von Frauen mit Brustkrebs bereits bei Behandlungsbeginn zu ermitteln, damit präventive Maßnahmen zur Frakturverhinderung frühzeitig eingeleitet werden können. Aromatase Inhibitoren (Al) gelten derzeit als Goldstandard in der Behandlung von postmenopausalen Frauen mit östrogenrezeptorpositiven Mammakarzinomen und haben hierbei das Tamoxifen weitestgehend verdrängt. Da Al massiv in den Östrogenstoffwechsel eingreifen, verhindern sie durch die weitestgehende Suppression der endogenen Östrogenspiegel das Wachstum von Tumorzellen. In randomisierten, kontrollierten klinischen Studien hat sich hierbei ein signifikanter Vorteil gegenüber Tamoxifen in Bezug auf das krankheitsfreie Überleben sowie auch auf das Gesamtüberleben in direkten Vergleichsstudien gezeigt. Im Gegensatz zum Tamoxifen besteht bei einer 5-jährigen Therapie mit Al ein deutlich erhöhtes Frakturrisiko. Die vorliegende Übersichtsarbeit fasst aktuelle Literatur in Bezug auf den Al-induzierten Knochendichteverlust zusammen und diskutiert die aktuellen internationalen Leitlinien zum Management und zur Prävention des Knochenverlustes und der Frakturverhinderung.

\begin{tabular}{ll}
\hline KARGER & $\oplus$ 2010 S. Karger GmbH, Freiburg \\
Fax +497614520714 & Accessible online at: \\
Information@Karger.de & www.karger.com/brc \\
www.karger.com &
\end{tabular}




\section{Introduction}

In the past, tamoxifen has been the treatment of choice for postmenopausal women (PMW) with hormone-sensitive breast cancer. Aromatase inhibitors (AIs) are increasingly used in the adjuvant setting as well as in switching treatment approaches, and are currently the gold standard as adjuvant endocrine therapy for PMW with hormone-sensitive breast cancer [1]. The estrogen receptor (ER) is expressed in a large proportion of breast tumors and has growth-promoting effects on tumor cells [2]. In about two thirds of all cases, breast cancer tumors are estrogen-sensitive [3]. Accordingly, many treatment strategies have focused upon hormonal ablation, antagonism of ER signaling, and suppression of estrogen synthesis [1].

The inhibition of the aromatase enzyme, which is responsible for the conversion of androgens to estrogen, leads to the prevention of estrogen synthesis with AIs [4]. Adjuvant therapy with third-generation AIs has largely replaced the use of tamoxifen as the gold standard for adjuvant endocrine treatment $[5,6]$. The third-generation AIs include the nonsteroidal formulations letrozole and anastrozole, and the steroidal formulation exemestane [4, 7]. Nearly complete suppression of plasma estrogen levels has been consistently demonstrated with all third-generation AIs [8-13]. A greater degree of estrogen suppression has been demonstrated with letrozole, when compared to a similar study with anastrozole [9]. Greater suppression of each tissue estrogen fraction was observed with letrozole in blood plasma as well as in tumor tissues [9]. The clinical significance of these differences remains uncertain.

AIs are now routinely used in 3 different postsurgical treatment approaches for patients with breast cancer including upfront monotherapy (5 years initial treatment with an AI), sequential adjuvant therapy (tamoxifen followed by an AI for a total of 5 years), and the extended adjuvant setting (using an AI after 5 years of tamoxifen) [6]. Superior clinical efficacy has been shown with all AIs compared to tamoxifen alone in each of these settings [14-21]. While there is clear evidence that inclusion of an AI in the treatment strategy, whether upfront or switching after tamoxifen, is superior to 5 years of tamoxifen alone, the optimal strategy for AI use remains unclear [22].

Following breast cancer surgery, there is long-term risk of recurrence with a first peak at 1-2 years [23]. The most common type of recurrence seen during this early peak is distant metastasis (DM), while locoregional and contralateral recurrences occur at a much lower rate [24]. This is important as $\mathrm{DM}$ is associated with increased mortality [25]. Therefore, therapies which reduce DM during this early peak of recurrence may have the potential to improve survival [25].

All AI therapies, both as initial and as sequential therapy, have improved disease-free survival (DFS) in women with breast cancer, however the effect on DM has not been uniform among AIs [14-17, 19, 20, 26-30].
Even though AI therapy has proven its superiority with regard to DFS compared to tamoxifene, AIs can also have longterm detrimental effects on bone health $[1,31,32]$. Bone loss is a predictable consequence of estrogen deprivation [33]. Estrogen has a regulatory effect on bone turnover. It leads to a clinically meaningful reduction of bone formation and bone resorption. Consequently, any therapy that depletes estrogen has the potential to increase bone resorption leading to bone loss, impacting bone integrity, and increasing the patient's risk of fracture. Postmenopausal breast cancer patients are already at an increased risk of osteoporosis due to age-related decrease of ovarian function, leading to a postmenopausal decline in estrogen levels, and estrogen depletion-related bone loss. Potential treatment-related bone loss may be an added risk factor (fig. 1) [2, 34-36]. Cancer treatment-induced bone loss (CTIBL) may be accentuated in women with breast cancer, who are receiving multiple forms of anticancer treatment (e.g. chemotherapy, endocrine therapy) [37]. For example, average lumbar spine (LS) bone mineral loss at 1 year has been reported to be between 1 and $2 \%$ in early and late PMW, compared with $7.7 \%$ in women with ovarian failure secondary to chemotherapy (fig. 1). AI-induced bone loss (AIBL) with endocrine therapy is associated with rapid bone loss and increased fracture risk that is distinctly different from that observed in postmenopausal osteoporosis (fig. 2) [2]. One of the most common side effects of AI use is skeletal bone loss leading to decrease of bone mineral density (BMD) followed by an increased risk of fractures (fig. 3) [6, 38, 39]. When combined with other treatments, this risk may be significantly enhanced. Eastell et al. [40] reported a 2.6\% loss in LS BMD in PMW with breast cancer receiving AI treatment. In comparison, a $7.0 \%$ loss was reported in women receiving AI therapy combined with a gonadotropin-releasing hormone $(\mathrm{GnRH})$ agonist [41].

The bone loss seen during AI treatment appears to be similar from one agent to the other within the fist 12-24 months, although there is a paucity of data from direct comparator trials $[19,42]$. A randomized trial of healthy volunteers
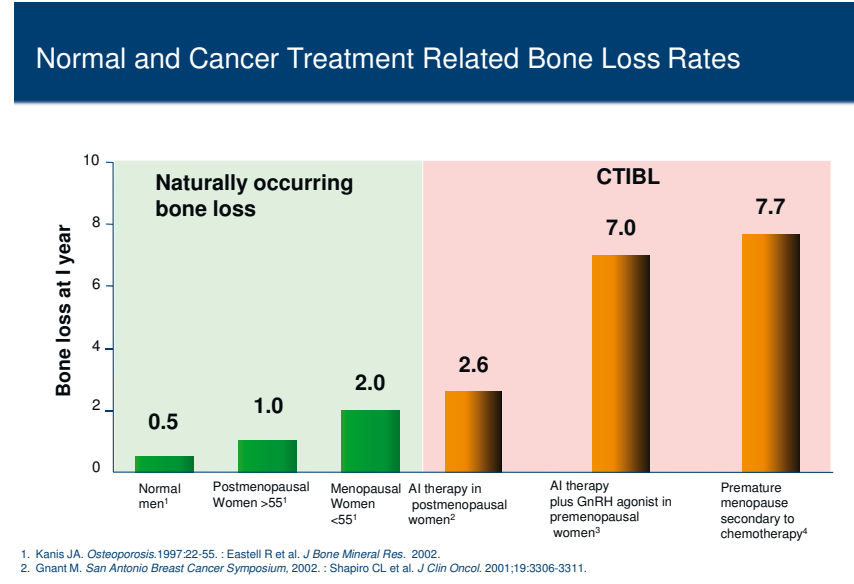

Fig. 1. Natural and cancer treatment induced bone loss (CTIBL). 


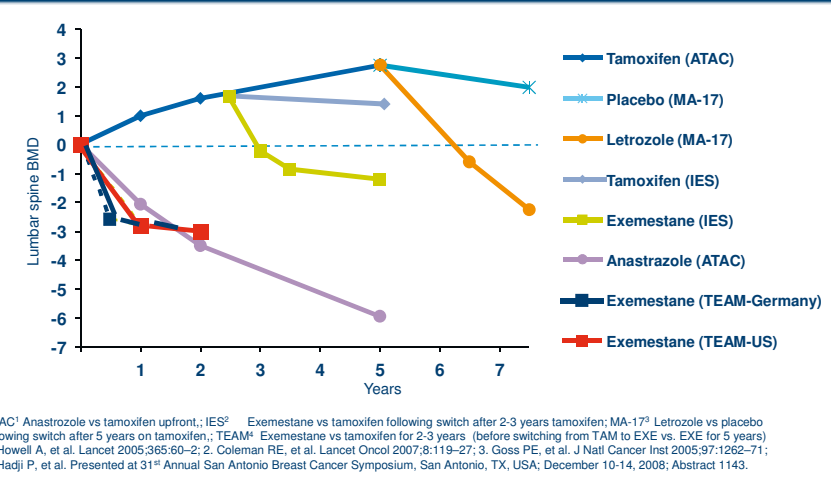

Fig. 2. Influence of aromatase inhibitors (AIs) on spine bone mineral density (BMD).

(Letrozole, Exemestane and Anastozole Pharmacodynamic (LEAP) Trial) demonstrated that all AIs (steroidal or nonsteroidal) have a similar effect on bone and are associated with increased bone turnover [43]. Recently, there has been greater awareness of the increased bone loss and fracture risk reported with the use of AI [44, 45]. Additionally, there is an increasing effort for proper management and intervention to reduce bone loss and prevent fragility fractures [31, 38, 46, 47]. This manuscript will review the recent literature pertaining to the risk of fractures and the premature or accelerated development of bone loss in patients treated with adjuvant AI therapy as well as recent management approaches.

\section{Al-Associated Bone Loss}

In PMW, the use of AIs increases bone turnover and induces bone loss at an average rate of $1-3 \%$ annually. This leads to an increase in fracture incidence compared to that seen during tamoxifen therapy [48]. Although the mechanism of action between the steroidal and non-steroidal AIs is somewhat different, adverse effects on bone health have been observed with all currently used AIs (fig. 3).

\section{Anastrozole}

The ATAC trial compared the efficacy and safety of anastrozole with that of tamoxifen in the initial adjuvant setting in PMW with early breast cancer $[14,26]$. After a median followup of 68 months, the fracture rate was $11 \%$ for patients treated with anastrozole $(n=3,092)$, versus $7.7 \%$ in patients treated with tamoxifen $(n=3,094)$ [14].

\section{Letrozole}

The BIG 1-98 trial is comparing letrozole with tamoxifen in the initial adjuvant setting. A significant difference in fracture rate was observed between letrozole $(5.7 \%)$ and the tamoxifen arm $(4.0 \% ; \mathrm{p}<0.001)$ at 25.8 months of median

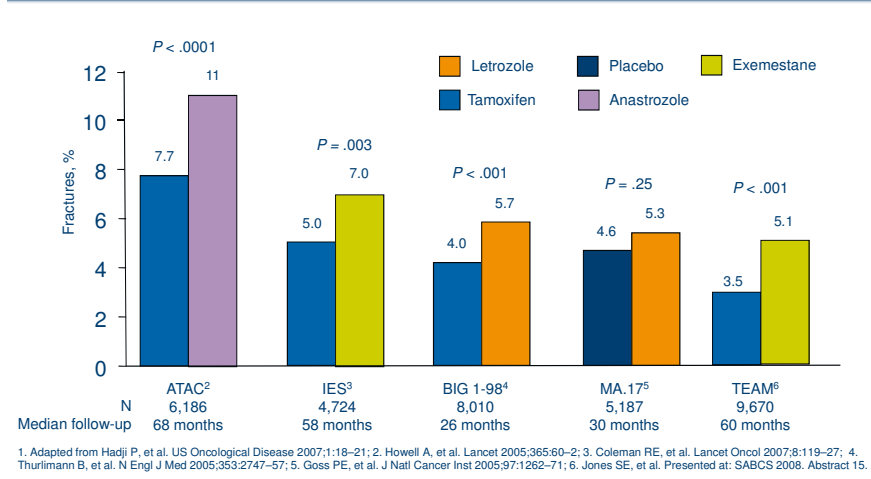

Fig. 3. Influence of aromatase inhibitors (AIs) on fracture risk.

follow-up [15]. At 51 months follow-up, letrozole $(\mathrm{n}=2,448)$ was associated with a significant 8.6 vs. $5.8 \%$ fracture rate with tamoxifen $(\mathrm{n}=2,447)(\mathrm{p}<0.001)$ [16]. At 5 years followup, the incidence of bone fractures remained significantly higher among patients treated with letrozole (9.3\% vs. tamoxifen 6.5\%; no p value reported) [49].

\section{Exemestane}

In the Intergroup Exemestane Study (IES), patients were randomized to either 5 years of tamoxifen $(n=2,372)$ or switching to exemestane following 2-3 years tamoxifen treatment $(\mathrm{n}=2,352)$ for a total of 5 years. Within 6 months of switching to exemestane, BMD was lowered by $2.7 \%$ at the LS and $1.4 \%$ at the hip compared to baseline values ( $\mathrm{p}<0.0001$ at both sites) [50]. All in all, 162 patients (7\%) in the exemestane arm and $115(5 \%)$ in the tamoxifen arm had fractures at a mean follow-up of 58 months $(p=0.01)$. In the TEAM trial, tamoxifen treatment resulted in a $0.5 \%$ increase from baseline in BMD at the spine, which was maintained at 12 months assessment $(\mathrm{n}=83)$. In contrast, exemestane treatment resulted in an increase in bone loss at 6 months $(2.6 \%$ decrease in spine BMD), and a further decrease of $0.2 \%$ at 12 months analysis $(n=78)$ [32]. In a recent subanalysis of the TEAM trial, exemestane resulted in increases from baseline in all bone turnover marker levels (e.g. bone-specific alkaline phosphatase, amino-terminal propeptide type I, procollagen, osteocalcin) at all time points [51]. In contrast, levels of all bone turnover markers decreased with tamoxifen treatment.

\section{Discussion}

Osteoporosis screening and treatment are a standard component of health maintenance in PMW, however, current treatment and preventative guidelines are inadequate for averting fractures in osteopenic women with breast cancer, especially those receiving AI therapy [52, 53]. Current American Society 
of Clinical Oncology (ASCO) treatment guidelines for maintaining bone health in women with breast cancer rely solely on BMD as an indicator of the need for antiresorptive therapy [54]. However, additional risk factors have been demonstrated in PMW that significantly increase fracture risk [55], suggesting that an osteoporotic T-score $(\leq-2.5)$ alone may fail to identify a large number of patients who are at increased risk. This is highlighted by the fact that the annual risk of hip fracture is independently influenced by the number of risk factors [55]. Osteoporosis treatment guidelines from the National Osteoporosis Foundation (NOF) and World Health Organization (WHO) suggest that it is important to include other risk factors along with BMD when assessing patient fracture risk and making treatment decisions $[56,57]$. Furthermore, because BMD measurements may not always be available or reimbursed, other risk factors must be considered to get a more complete understanding of clinically relevant risk factors for fracture, which will help to assess overall fracture risk and provide practical guidance for the prevention and treatment of bone loss in this population $[31,52,53]$.

In order to place BMD assessments and other risk factors within the context of identifying women with breast cancer, who are at increased risk of fracture and who are likely candidates for preventative therapy, a panel of experts recently evaluated data from large clinical trials in PMW and women with breast cancer to develop consensus international guidelines for using clinical risk factors for fracture along with BMD measurements [31]. A systematic review of published literature to identify factors that contribute to fracture risk in women with breast cancer has been reported previously. PubMed $^{\circledR}$ searches of MEDLINE ${ }^{\circledR}$ (National Library of Medicine, Bethesda, MD, USA) and other databases were performed to identify clinical trials of antiresorptive agents used for the prevention and treatment of AIBL from June 2008 through June 2010. Additional information was obtained from abstracts presented at international meetings including the St. Gallen Breast Cancer Conference, European Breast Cancer Conference (EBCC), San Antonio Breast Cancer Symposium (SABCS), and ASCO annual meetings and breast cancer symposia. An evidence-based medicine approach was used to determine when to initiate antiresorptive therapy for AIBL, to determine the appropriate antiresorptive therapy, and to define follow-up/monitoring procedures. All authors reviewed the available evidence and as a group reached a consensus regarding the levels of evidence and treatment recommendations (fig. 4). Eight risk factors were validated in women with breast cancer [31] including AI therapy, T score $<-1.5$, age $>65$ years, low body mass index $\left(\mathrm{BMI}<20 \mathrm{~kg} / \mathrm{m}^{2}\right)$, family history of hip fracture, personal history of fragility fracture after age 50, oral corticosteroid use $>6$ months, and smoking (table 1). These current guidelines underscore the importance of comprehensive fracture risk assessments and advocate BMD measurements in all patients taking AIs with selective use of antiresorptive therapy in osteoporotic ( $\mathrm{T}$ score
Recommendations for Women With Breast Cancer Initiating Aromatase Inhibitor Therapy

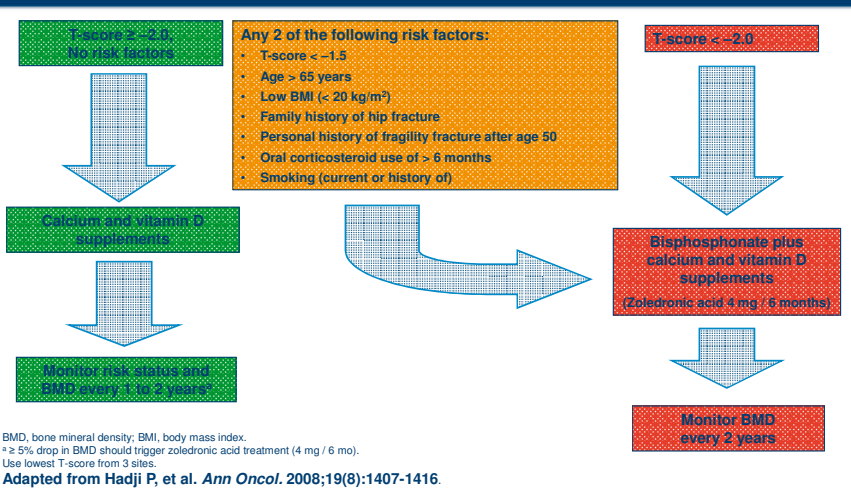

Fig. 4. Recommended management strategy for patients with breast cancer receiving aromatase inhibitor (AI) therapy [31]. These recommendations are based on results from trials in breast cancer patients and healthy populations. The largest body of evidence for treatment of AI-associated bone loss is for zoledronic acid $4 \mathrm{mg}$ every 6 months ( ${ }^{\mathrm{a}}$ If patients experience an annual decrease in bone mineral density (BMD) of $\geq 5 \%$ (using the same dual-energy $X$-ray absorptiometry machine), secondary causes of bone loss such as vitamin D deficiency should be evaluated and bisphosphonate therapy considered. Use lowest T-score from 3 sites ; BMI = body mass index).

Table 1. Fracture risk factors in women with breast cancer [31]

\begin{tabular}{ll}
\hline Validated risk factors $^{\mathrm{a}}$ & Possible risk factors $^{\mathrm{b}}$ \\
\hline AI therapy & $\begin{array}{l}\text { chemotherapy } \\
\text { radiotherapy } \\
\text { T score }<-1.5\end{array}$ \\
Age $>65$ years & \\
Low BMI $\left(<20 \mathrm{~kg} / \mathrm{m}^{2}\right)$ & \\
Family history of hip fracture & \\
Personal history of fragility fracture after age 50 \\
Oral corticosteroid use $>6$ months \\
Smoking (current and history of) \\
${ }^{\mathrm{a}}$ Validated in large clinical trials of healthy postmenopausal women \\
(except AI therapy). \\
${ }^{\mathrm{b} C o u l d ~ n o t ~ b e ~ v a l i d a t e d ~ b e c a u s e ~ o f ~ i n s u f f i c i e n t ~ t r i a l ~ d a t a . ~}$ \\
AI = Aromatase inhibitor; BMI = body mass index. \\
\hline
\end{tabular}

$<-2.5)$ women [46, 58]. Evaluating both BMD and clinical risk factors may allow for the most effective identification of breast cancer patients with increased risk of fracture and the appropriate use of preventative therapies [59].

Mounting evidence now suggests that treatment with bisphosphonates prevents AIBL [2, 22, 46, 60-65]. Because of the increased bone loss associated with the use of AIs, three international randomized studies, the Zometa-Femara Adjuvant Synergy Trials [Z-FAST, ZO-FAST, and E-ZOFAST] were performed to evaluate the bone protective effects of bisphosphonates during endocrine treatment with letrozole. The primary endpoint of these companion trials was to determine the impact of upfront or delayed (if $\mathrm{T}$ score $<-2.0$ or in the presence of a fracture) treatment of zoledronic 
acid (ZOL: $4 \mathrm{mg}$ intravenously every 6 months) on BMD at 12 months at the LS in PMW $(n=2,194)$ with hormonesensitive breast cancer receiving letrozole. Secondary endpoints included fracture rate, DFS, and disease recurrence. These studies have all shown that the BMD loss associated with AI therapy can effectively be prevented by adjuvant treatment with ZOL. Current management guidelines now recommend that any patient initiating or receiving AI therapy with any two identified risk factors should receive bisphosphonate therapy [31].

The results of the Z-FAST study demonstrate a continuous annual BMD increase at both the LS and total hip (TH) in the patients who were receiving upfront ZOL $(\mathrm{n}=301)$ versus delayed treatment $(n=301)$ [63]. Long-term, 5-year follow-up data confirm that, compared with delayed-start, upfront ZOL (4 mg intravenously every 6 months) effectively prevents/ treats bone loss in PMW, regardless of baseline T score, chemotherapy status, or osteoporotic risk factor frequency [63]. The results show a progressive and significantly increased LS and TH BMD over 5 years with upfront ZOL treatment (percent change in LS and TH BMD from baseline at 61 months: 6.19 and $2.57 \%$, respectively; $p<0.0001$ ) [63]. Similarly, in the ZO-FAST study $(\mathrm{n}=1,065)$, there were significant increases in BMD in favor of upfront ZOL compared with delayed ZOL at 48 months (LS: 9.29\%, p < 0.0001; TH: $5.41 \%$, $\mathrm{p}<0.0001)[66]$

The Study of Anastrozole with the Bisphosphonate RisedronatE (SABRE) compared the efficacy of risedronate ( $35 \mathrm{mg} /$ week orally) versus placebo for 2 years in PMW with hormone receptor-positive early breast cancer receiving adjuvant anastrozole, who also had a moderate risk of fragility fracture $(n=154)$ [65]. At 24 months, oral risedronate significantly increased LS BMD by $2.2 \%$ and TH BMD by $1.8 \%$ versus baseline ( $\mathrm{p}<0.0001$ for each vs. placebo). A similar trial in PMW with breast cancer receiving AI therapy demonstrated that oral risedronate (35 $\mathrm{mg} /$ week) initially improved BMD versus baseline, but only modestly increased LS BMD (0.4\%) and TH BMD (0.9\%) at 24 months [61]. Among patients enrolled in the International Breast Cancer Intervention Study (IBIS-II) bone substudy ( $\mathrm{n}=613$ ), women with osteopenia $(n=59)$ receiving anastrozole plus risedronate $(35 \mathrm{mg} /$ week) had better LS $(0.32 \%)$ and TH $(0.67 \%)$ BMD compared with women receiving anastrozole alone [39]. In the 24-month analysis of the Arimidex-Bondronat (ARIBON) study, monthly oral ibandronate $(150 \mathrm{mg})$ prevented bone loss in osteopenic women $(\mathrm{n}=25)$ compared with placebo $(\mathrm{n}=25)$ and in a small number of patients with pre-existing osteoporosis $(n=13)$ [67]. Oral ibandronate increased LS
BMD by $2.98 \%$ and TH BMD by $0.60 \%$. In all of the studies of oral bisphosphonates, patients who did not receive a bisphosphonate experienced substantial BMD loss during AI therapy.

The HALT-BC trial $(\mathrm{n}=252)$ examined the efficacy of biannual denosumab (60 mg subcutaneously every 6 months) versus placebo for prevention of AIBL in PMW with early breast cancer receiving AI therapy [68]. At 24 months followup, there was a significant $7.6 \%$ difference in LS BMD between the denosumab and placebo groups $(p<0.0001)$. Although the BMD change is not precisely defined, this between-group difference equates to an approximate $6.2 \%$ BMD increase with denosumab versus an approximate $1.4 \%$ BMD loss with placebo. The ongoing ABCSG-18 trial (NCT00556374) will compare denosumab with placebo in 3,400 PMW receiving adjuvant AI therapy, and should provide additional data to confirm the efficacy and determine the long-term safety of this novel antiresorptive agent.

\section{Conclusion}

Adjuvant treatment of hormone receptor-positive breast cancer in PMW with AIs has now become the standard of care due to superior DFS results and a more favorable side effect profile compared with tamoxifen. Due to the profound estrogen depletion achieved with AI therapy, however, negative effects on bone health may also be observed. Screening and medical management for bone complications in breast cancer patients being treated with AIs is therefore an important area for clinical intervention. The presence of risk factors (e.g. age, $\mathrm{T}$ score, BMI, family and personal history, smoking) may be used for appropriate patient stratification and the determination of an optimal treatment plan to preserve bone integrity. Several studies have demonstrated the efficacy of antiresorptive agents (e.g. bisphosphonates, denosumab) for the prevention of BMD loss and reduction of fracture risk associated with breast cancer therapy. Although no treatments are specifically approved for AIBL, patients at high risk for rapid bone loss may benefit from early and sustained intravenous bisphosphonate therapy. Adequate calcium and vitamin D supplementation and a healthy lifestyle are also required to maintain long-term bone health. In addition to the positive effects on bone health, there is now also a growing body of evidence supporting the potential anticancer benefits of bisphosphonate therapy. Therefore, patients may derive dual benefit both from bone health improvement and anticancer activity. 


\section{References}

1 Clunie GP, Clark A, Mortimer CJ, Stephenson S, Aitken J, Smith C, Sherwin E, Archer TJ: Evaluating bone health in women with oestrogen receptor positive breast cancer (ERBC) starting aromatase inhibitors. Eur J Surg Oncol 2009;35:475-80.

$\checkmark 2$ Hadji P: Aromatase inhibitor-associated bone loss in breast cancer patients is distinct from postmenopausal osteoporosis. Crit Rev Oncol Hematol 2009;69:73-82.

$>3$ Folkestad L, Bjarnason NH, Bjerregaard JK, Brixen K: The effect of aromatase inhibitors on bone metabolism. Basic Clin Pharmacol Toxicol 2008;104:3-10.

4 Miller WR, Bartlett J, Brodie AMH, Breuggemeier RW, Di Salle E, Lonning PE, Llombart A, Maass N, Maudelonde T, Sasano H, Goss PE: Aromatase inhibitors: are there differences between steroidal and nonsteroidal aromatase inhibitors and do they matter? Oncologist 2008;13:829-37.

5 Janni W, Hepp P: Adjuvant aromatase inhibitor therapy: outcomes and safety. Cancer Treat Rev 2010;36:249-61.

6 Conte P, Frassoldati A: Aromatase inhibitors in the adjuvant treatment of postmenopausal women with early breast cancer: putting safety into perspective. Breast J 2007;13:28-35.

7 Ozair S, Iqbal S: Efficacy and safety of aromatase inhibitors in early breast cancer. Expert Opin Drug Saf 2008;7:547-58.

$>$ Macedo LF, Sabnis G, Brodie A: Aromatase inhibitors and breast cancer. Ann N Y Acad Sci 2009;1155:162-73.

$\checkmark$ Geisler J. Aromatase inhibitors: from bench to bedside and back. Breast Cancer 2008;15:17-26.

${ }_{10}$ Geisler J, King N, Dowsett M, Ottestad L, Lundgren S, Walton P, Kormeset PO, Lønning PE: Influence of anastrozole (Arimidex), a selective, non-steroidal aromatase inhibitor, on in vivo aromatisation and plasma oestrogen levels in postmenopausal women with breast cancer. $\mathrm{Br} \mathrm{J}$ Cancer 1996;74:1286-91.

-11 Geisler J, King N, Anker G, Ornati G, Di Salle E, Lønning PE, Dowsett M: In vivo inhibition of aromatization by exemestane, a novel irreversible aromatase inhibitor, in postmenopausal breast cancer patients. Clin Cancer Res 1998;4:2089-93.

- 12 Geisler J, Haynes B, Anker G, Dowsett M, Lonning PE: Influence of letrozole and anastrozole on total body aromatization and plasma estrogen levels in postmenopausal breast cancer patients evaluated in a randomized, cross-over study. J Clin Oncol 2002;20:751-7.

13 Dowsett M, Jones A, Johnston SR, Jacobs S, Trunet P, Smith IE: In vivo measurement of aromatase inhibition by letrozole (CGS 20267) in postmenopausal patients with breast cancer. Clin Cancer Res 1995;1:1511-5.

14 Howell A, Cuzick J, Baum M, et al.; ATAC Trialists' Group: Results of the ATAC (Arimidex, Tamoxifen, Alone or in Combination) trial after completion of 5 years' adjuvant treatment for breast cancer. Lancet 2005;365:60-2.

15 Thürlimann B, Keshaviah A, Coates AS, Mouridsen H, Mauriac L, Forbes JF, Paridaens R, Castiglione-Gertsch M, Gelber RD, Rabaglio M, Smith I, Wardley A, Price KN, Goldhirsch A; Breast International Group (BIG) 1-98 Collaborative Group: A comparison of letrozole and tamoxifen in postmenopausal women with early breast cancer. N Engl J Med 2005;353:2747-57.
Coates AS, Keshaviah A, Thurlimann B, et al.: Five years of letrozole compared with tamoxifen as initial adjuvant therapy for postmenopausal women with endocrine-responsive early breast cancer: update of study BIG1-98. J Clin Oncol 2007;25:486-92.

17 Mouridsen H, Giobbie-Hurder A, Goldhirsch A, Thürlimann B, Paridaens R, Smith I, Mauriac L, Forbes JF, Price KN, Regan MM, Gelber RD, Coates AS; BIG 1-98 Collaborative Group: Letrozole therapy alone or in sequence with tamoxifen in women with breast cancer. N Engl J Med 2009;361:766-76.

18 Boccardo R, Rubagotti A, Puntoni M, et al.: Switching to anastrozole versus continued tamoxifen treatment of early breast cancer: preliminary results of the Italian Tamoxifen Anastrozole Trial. J Clin Oncol 2005;23:5138-47.

19 Coombes RC, Hall E, Gibson LJ, et al.: Intergroup Exemestane Study. A randomized trial of exemestane after two to three years of tamoxifen therapy in postmenopausal women with primary breast cancer. N Engl J Med 2004;350:1081-92; erratum N Engl J Med 2004;351:2461.

20 Coombes RC, Kilburn LS, Snowdon CF, et al.: Intergroup Exemestane Study. Survival and safety of exemestane versus tamoxifen after 2-3 years' tamoxifen treatment (Intergroup Exemestane Study): a randomised controlled trial. Lancet. 2007;369:559-570; erratum Lancet 2007;369:906.

21 Jones SE, Seynaeve C, Hasenburg A, Rae D, Vannetzel J-M, Paridaens R, Markopoulos C, Hozumi Y, Putter H, Hille E, Kieback D, Asmar L, Smeets J, Urbanski R, Bartlett MJS, van de Velde CJH: Results of the first planned analysis of the TEAM (tamoxifen exemestane adjuvant multinational) prospective randomized phase III trial in hormone sensitive postmenopausal early breast cancer. Cancer Res 2009;69(suppl 2):67s(abstr 15).

22 Chlebowski R, Cuzick J, Amakye D, Bauerfeind I, Buzdar A, Chia S, Cutuli B, Linforth R, Maass N, Noguchi S, Robidoux A, Verma S, Hadji P: Clinical perspectives on the utility of aromatase inhibitors for the adjuvant treatment of breast cancer. Breast 2009;18(suppl 2):S1-11.

23 Saphner T, Tormey DC, Gray R: Annual hazard rates of recurrence for breast cancer after primary therapy. J Clin Oncol 1996;14:2738-46.

24 Mansell J, Monypenny IJ, Skene AI, Abram P, Carpenter R, Gattuso JM, Wilson CR, Angerson WJ, Doughty JC: Patterns and predictors of early recurrence in postmenopausal women with estrogen receptor-positive early breast cancer. Breast Cancer Res Treat 2009;117:91-8.

25 Lamerato L, Havstad S, Gandhi S, Jones D, Chlebowski R: Breast cancer recurrence and related mortality in US pts with early breast cancer. J Clin Oncol 2005;23:62s(abstr 738).

26 Baum M, Buzdar A, Cuzick J, et al.: Anastrozole alone or in combination with tamoxifen versus tamoxifen alone for adjuvant treatment of postmenopausal women with early-stage breast cancer: results of the ATAC (Arimidex, Tamoxifen Alone or in Combination) trial efficacy and safety update analyses. Cancer 2003;98:1802-10.

27 Goss PE, Ingle JN, Martino S, Robert NJ, et al.: Randomised trial of letrozole following tamoxifen as extended adjuvant therapy in receptor-positive breast cancer: updated findings from NCIC CTG MA.17. J Natl Cancer Inst 2005;97:1262-71.
Jakesz, R, Jonat W, Gnant M, Mittlboeck M, Greil R, Tausch C, Hilfrich J, Kwasny W, Menzel C, Samonigg H, Seifert M, Gademann G, Kaufmann M, Wolfgang J; ABCSG and the GABG: Switching of postmenopausal women with endocrine-responsive early breast cancer to anastrozole after 2 years' adjuvant tamoxifen: combined results of ABCSG trial 8 and ARNO 95 trial. Lancet 2005;366:455-62.

29 Forbes JF, Cuzick J, Buzdar A, Howell A, Tobias JS, Baum M; The Arimidex, Tamoxifen, Alone or in Combination (ATAC) Trialists' Group: Effect of anastrozole and tamoxifen as adjuvant treatment for early-stage breast cancer: 100-month analysis of the ATAC trial. Lancet Oncol 2008a;9:45-53.

30 Jonat W, Hilpert F, Kaufmann M: Aromatase inhibitiors: a safety comparison. Expert Opin Drug Saf 2007;6:165-74.

31 Hadji P, Body JJ, Aapro MS, Brufsky A, Coleman RE, Guise T, Lipton A, Tubiana-Hulin M Practical guidance for the management of aromatase inhibitor-associated bone loss. Ann Oncol 2008;19:1407-16.

32 Hadji P, Ziller M, Kieback DG, et al.: Effects of exemestane and tamoxifen on bone health within the Tamoxifen Exemestane Adjuvant Multicentre (TEAM) trial: results of a German, 12-month, prospective, randomised substudy. Ann Oncol 2009;20:1203-9.

33 Delaney MF: Strategies for the prevention and treatment of osteoporosis during early postmenopause. Am J Obstet Gynecol 2006;194(2 suppl):S12-23. Review.

34 Gibson K, O'Bryant CL: Screening and management of osteoporosis in breast cancer patients on aromatase inhibitors. J Oncol Pharm Pract 2008;14:139-45.

35 Gralow JR, Biermann JS, Farooki A, Fornier MN, Gagel RF, Kumar RN, Shapiro CL, Shields A, Smith MR, Srinivas S, Van Poznak CH; NCCN Task Force Report: Bone Health in Cancer Care: J Natl Compr Canc Netw 2009;7(suppl 3):S1-S32; quiz S33-S35.

36 Geisler J, Lonning PE: Impact of aromatase inhibitors on bone health in breast cancer patients. J Steroid Biochem Mol Biol 2010;118:294-9.

37 Bertoldo F, Pancheri S, Zenari S, Boldini S: Emerging drugs for the management of cancer treatment induced bone loss. Expert Opin Emerging Drugs 2010;15:323-42. Review.

38 Yamamoto DS, Hallquist Viale P: Update on identifying and managing osteoporosis in women with breast cancer. Clin J Oncol Nurs 2009;13:E18-E29.

39 Rugo HS: The breast cancer continuum in hormone-receptor-positive breast cancer in postmenopausal women: evolving management options focusing on aromatase inhibitors. Ann Oncol 2008;19:16-27.

40 Eastell R, Hannon RA, Cuzick J, et al.: Effect of anastrozole on bone density and bone turn over: results of the 'Arimidex' (anastrozole), Tamoxifen, Alone or in Combination (ATAC) study. J Bone Miner Res 2002;17(suppl 1):S165.

41 Gnant M, Hausmaninger H, Samonigg H: Changes in bone mineral density caused by anastrozole or tamoxifen in combination with goserelin $(+/-$ zoledronate as adjuvant treatment for hormone receptor-positive premenopausal breast cancer: results of a randomized multicenter trial. Breast Cancer Res Treat 2002;76(suppl 1):S31(abstr 12). 
42 McCaig FM, Renshaw, Williams L, Young O, Murray J, Macaskill EJ, McHugh M, Hannon R, Dixon JM: A randomized study of the effects of anastrozole (A), letrozole (L) and exemestane (E) on bone turnover. Cancer Res 2009;69(suppl 2):148s-149s(abstr 1145).

43 McCloskey E, Hannon R, Lakner G, Clack G, Miyamoto A, Eastell R: Interaction between body mass index and bone turnover during aromatase inhibition: evidence from the letrozole (L), exemestane (E), and anastrozole (A) pharmacodynamics (LEAP) trial. J Clin Oncol 2007;25(18S):17S(abstr 560).

44 Reid DM: Prevention of osteoporosis after breast cancer. Maturitas 2009;64:4-8.

45 Coleman RE, Body JJ, Gralow JR, Lipton A: Bone loss in patients with breast cancer receiving aromatase inhibitors and associated treatment strategies. Cancer Treat Rev 2008:34(suppl 1):S31-42.

46 Bundred NJ: Aromatase inhibitors and bone health. Curr Opin Obstet Gynecol 2009;21:60-7.

47 Abdulhaq H, Geyer C: Safety of adjuvant endocrine therapy in postmenopausal women with breast cancer. Am J Clin Oncol 2008;31:595-605.

48 Eastell R, Hannon RA, Cuzick J, Dowsett M, Clack G, Adams JE; ATAC Trialists' group: Effect of an aromatase inhibitor on BMD and bone turnover markers: 2-year results of the Anastrozole, Tamoxifen, Alone or in Combination (ATAC) trial (182332030). J Bone Miner Res 2006;21:121523.

49 Rabaglio M, Sun Z, Price KN, Castiglione-Gertsch M, Hawle H, Thürlimann B, Mouridsen H, Campone M, Forbes JF, Paridaens RJ, Colleoni M, Pienkowski T, Nogaret JM, Láng I, Smith I, Gelber RD, Goldhirsch A, Coates AS; BIG 1-98 Collaborative and International Breast Cancer Study Groups: Bone fractures among postmenopausal patients with endocrine-responsive early breast cancer treated with 5 years of letrozole or tamoxifen in the BIG 1-98 trial. Ann Oncol 2009;20:148998.

50 Coleman RE, Banks LM, Girgis SI, et al.: Skeleta effects of exemestane on bone-mineral density, bone biomarkers, and fracture incidence in postmenopausal women with early breast cancer participating in the Intergroup Exemestane Study(IES): a randomized controlled study. Lancet Oncol 2007;8:119-27.
51 Hadji P, Ziller M, Kieback DG, et al.: The effect of exemestane or tamoxifen on markers of bone turnover: results of a German sub-study of the Tamoxifen Exemestane Adjuvant Multicentre (TEAM) trial. Breast 2009a;18:159-64.

52 Pant S, Shapiro CL: Aromatase inhibitor-associated bone loss: clinical considerations. Drugs 2008;68:2591-600.

53 Yamamoto Y, Iwase H: Safety profiles of aromatase inhibitors and selective estrogen-receptor modulators in the treatment of early breast cancer. Int J Clin Oncol 2008;13:384-94.

54 Hillner BE, Ingle JN, Chlebowski RT, et al.: American Society of Clinical Oncology 2003 update on the role of bisphosphonates and bone health issues in women with breast cancer. J Clin Oncol 2003;21:4042-57.

55 Cummings SR, Nevitt MC, Browner WS, et al.: Risk factors for hip fracture in white women. N Engl J Med 1995;332:767-73.

56 National Osteoporosis Foundation: Physician's Guide: Pharmacologic Options. www.nof.org/ physguide/pharmacologic.htm; accessed October 4, 2007.

57 World Health Organization: Technical Report Series 921: Prevention and Management Osteoporosis. Geneva, WHO, 2003, pp. 1-192.

58 Aapro M, Abrahamsson PA, Body JJ, Coleman RE, Colomer R, Costa L, Crino L, Dirix L, Gnant M, Gralow J, Hadji P, Hortobagyi GN, Jonat W, Lipton A, Monnier A, Paterson AHG, Rizzoli R, Saad F, Thurlimann B: Guidance on the use of bisphosphonates in solid tumours: recommendations of an international expert panel. Ann Oncol 2008;19:420-32.

59 Hadji P, Ziller M, Albert US, Kalder M: Assessment of fracture risk in women with breast cancer using current vs. emerging guidelines. Br J Cancer 2010;102:645-50.

60 Saarto T, Vehmanen L, Elomaa I, et al.: The effect of clodronate and antioestrogens on bone loss associated with oestrogen withdrawal in postmenopausal women with breast cancer. Br J Cancer 2001;84:1047-51.

61 Greenspan SL, Brufsky A, Lembersky BC, et al.: Risedronate prevents bone loss in breast cancer survivors: a 2-year, randomized, double-blind, placebo-controlled clinical trial. J Clin Oncol 2008;26:2644-52.
62 Brufsky AM, Bosserman LD, Caradonna RR, Haley BB, Jones CM, Moore HC, Jin L, Warsi GM, Ericson SG, Perez EA: Zoledronic acid effectively prevents aromatase inhibitor-associated bone loss in postmenopausal women with early breast cancer receiving adjuvant letrozole: Z-FAST study 36-month follow-up results. Clin Breast Cancer 2009;9:77-85.

63 Brufsky A, Harker WG, Beck JT, Carroll R, Jin L, Warsi G Argonza-Aviles E, Ericson SG, Perez EA; Z-FAST Study Group: The effect of zoledronic acid on aromatase inhibitor-associated bone loss in postmenopausal women with early breast cancer receiving adjuvant letrozole: the Z-FAST study 5-year final follow-up. 32nd Annual San Antonio Breast Cancer Symposium, San Antonio, TX, USA; December 9-13, 2009; abstr 4083.

64 Bundred NJ, Campbell ID, Davidson N, DeBoer RH, Eidtmann H, Monnier A, Neven P, von Minckwitz G, Miller JC, Schenk NL, Coleman RE: Effective inhibition of aromatase inhibitor-associated bone loss by zoledronic acid in postmenopausal women with early breast cancer receiving adjuvant letrozole: ZO-FAST Study results. Cancer 2008;112:1001-10.

65 Van Poznak C, Hannon RA, Mackey JR, et al. Prevention of aromatase inhibitor-induced bone loss using risedronate: the SABRE trial. J Clin Oncol 2010;28:967-75.

66 Eidtmann H, de Boer R, Bundred N, LlombartCussac A, Davidson N, Neven P, von Minckwitz G, Miller J, Schenk N, Coleman R: Efficacy of zoledronic acid in postmenopausal women with early breast cancer receiving adjuvant letrozole: 36 month results of the ZO-FAST Study. Ann Oncol 2010. Epub ahead of print. 